\title{
Pericardial cyst on the left heart border
}

\author{
T. H. Pinxterhuis - A. P. van der Weerdt - C. A. da Fonseca
}

Published online: 13 June 2019

(C) The Author(s) 2019

A 65-year-old female was admitted with progressive exertional dyspnoea and chest pain. Chest radiography revealed an enlarged cardiac silhouette suspicious for a large pericardial effusion (Fig. 1a). Transthoracic echocardiogram was normal, apart from a large echolucent space strictly limited to the anterolateral border of the left ventricle (Fig. 1b). Computed tomography scan showed a large cystic mass at the left heart border $(17 \times 7 \mathrm{~cm}$, see Fig. 1c). Patient underwent video-assisted thoracic surgery in which the entire cyst was removed. During surgery the diagnosis pericardial cyst was confirmed. Chest radiography afterwards showed a normal heart contour (Fig. 1d).

Pericardial cysts are mostly diagnosed in women around 50 years [1]. Ninety percent of the patients are asymptomatic. If symptoms occur, chest pain is most common, followed by dyspnoea and palpitations [1].
Pericardial cysts are located in the right heart border in $80 \%$, less frequently in the left heart border (15\%) and, rarely, in the anterior mediastinum [1].

Conflict of interest T.H. Pinxterhuis, A.P. van der Weerdt and C.A. da Fonseca declare that they have no competing interests.

Open Access This article is distributed under the terms of the Creative Commons Attribution 4.0 International License (http://creativecommons.org/licenses/by/4.0/), which permits unrestricted use, distribution, and reproduction in any medium, provided you give appropriate credit to the original author(s) and the source, provide a link to the Creative Commons license, and indicate if changes were made.

\section{References}

1. Alkharabsheh S, Gentry JL III., Khayata M, et al. Clinical features, natural history, and management of pericardial cysts. Am J Cardiol. 2019;123(1):159-63. 

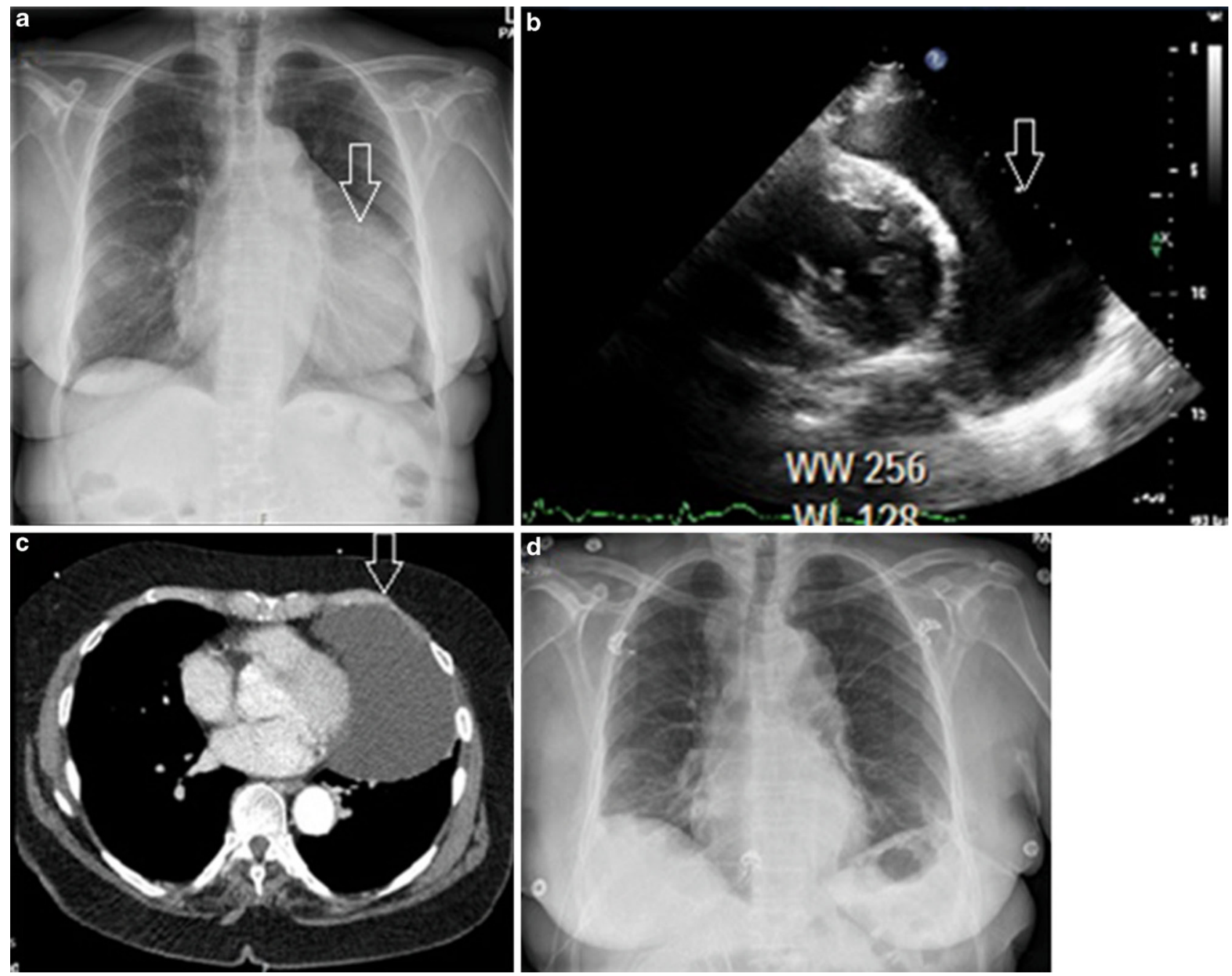

Fig. 1 a Chest radiography showing an enlarged cardiac silhouette, $\mathbf{b}$ TTE showing the presence of an echo-lucent space adjacent to the left ventricle, $\mathbf{c}$ CT heart image showing a lobulated, low-signal-intensity, cystic mass within the pericardium

to the left of the left heart border, $\mathbf{d}$ Chest radiography showing a normal heart contour after surgical removal of the pericardial cyst (CT computed tomography, TTE transthoracic echocardiography) 